\title{
Novel Synthesis of Gel Capsule by Thermal Acid-Catalyzed Deesterification of Poly(t-butyl methacrylate) Gel
}

\author{
Takashi IIzawa, ${ }^{\dagger}$ Takashi Fusimoto, and Fumihiko Matsuda \\ Department of Chemical Engineering, Faculty of Engineering, Hiroshima University, \\ Kagamiyama, Higashi-Hiroshima 739, Japan
}

(Received March 26, 1997)

\begin{abstract}
KEY WORDS Gel Capsule / Thermal Acid-Catalyzed Deesterification/Poly(t-butyl methacrylate) / Chemical Release /
\end{abstract}

Poly( $t$-butyl methacrylate) (PBM) is poly(methacrylic acid) (PMAA) protected by $t$-butyl group. Deprotection of the polymer occurs easily in the presence of acid catalyst, causing solubility and polarity to change dramatically. This characteristic attracts attention to a functional polymer such as chemically amplified resist. ${ }^{1}$ Ito et $a .^{2}{ }^{2}$ investigated the thermal acid-catalyzed deesterification of PBM in the film state, and tried to apply the deesterification to a chemically amplified resist. However, other application has hardly been reported.

In a previous paper, ${ }^{3}$ we designed a new amphiphilic core-shell typed gel "gel capsule" consisting of a hydrophilic core gel covered and bound chemically with hydrophobic shell layer. This gel was successfully synthesized by the selective esterification of external 1,8diazabicyclo-[5,4,0]-7-undecene salt of poly(acrylic acid) gel with alkyl halide in a solvent, and the resulting shell layer worked as a permeability barrier to water.

This communication reports a novel synthetic method of gel capsule by the thermal acid-catalyzed deesterification of poly ( $t$-butyl methacrylate) gel (GPBM). Selective deesterification from the inner gives a core-shell typed gel consisting of a hydrophilic deesterified core and unreacted hydrophobic shell (Scheme 1). We discuss the release of chemicals from the gel.

$t$-Butyl methacrylate $(94.3 \mathrm{~g}, 0.66 \mathrm{~mol})$, divinylbenzene $(4.5 \mathrm{~g}, 35 \mathrm{mmol})$, and $2,2^{\prime}$-azobis(isobutyronitrile) $(1.9 \mathrm{~g})$ were dissolved in toluene $(400 \mathrm{ml})$. The solution was charged in a separable flask with Teflon tubes (internal diameter, $6 \mathrm{~mm}$; length, about $6 \mathrm{~cm}$ ). The reaction mixture was allowed to stand at $50^{\circ} \mathrm{C}$ for $12 \mathrm{~h}$ and consecutively at $60^{\circ} \mathrm{C}$ for $36 \mathrm{~h}$ under nitrogen stream. After completion of gelation, the gel bars in the tubes were taken out of the resulting gel. The gel bars with tubes were cut to give cylindrical samples $6 \mathrm{~mm}$ long with the tubes. Each sample was pushed out from the tube and immersed in a large amount of toluene to wash away unreacted substances. The sample was dipped into a suitable concentration of $p$-toluenesulfonic acid solution in tetrahydrofuran. The gel was dried carefully and slowly, being easily damaged.

A typical deesterification is as follows: Alkyl acetate $(40 \mathrm{~mL})$ was charged into a $50 \mathrm{~mL}$ cylindrical cell in a chamber at $110^{\circ} \mathrm{C}$. To the solvent was added a gel sample

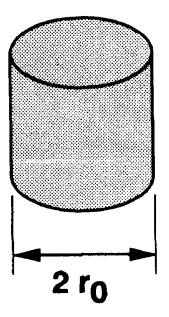

$90^{\circ} \mathrm{C}-120^{\circ} \mathrm{C}$

in alkyl acetate
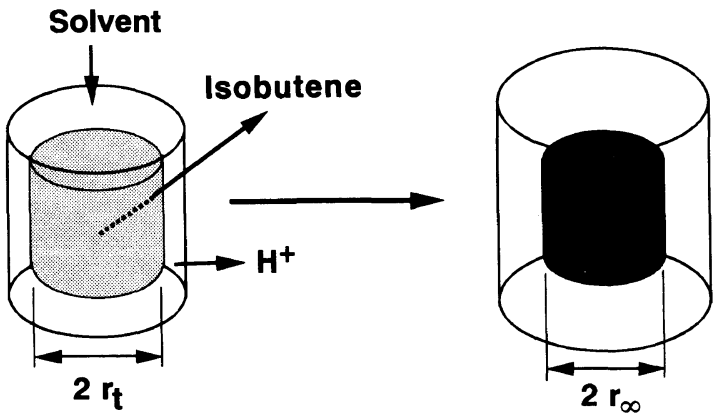

Part containing acid catalyst

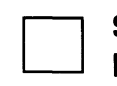

Swollen (unreacted)
part
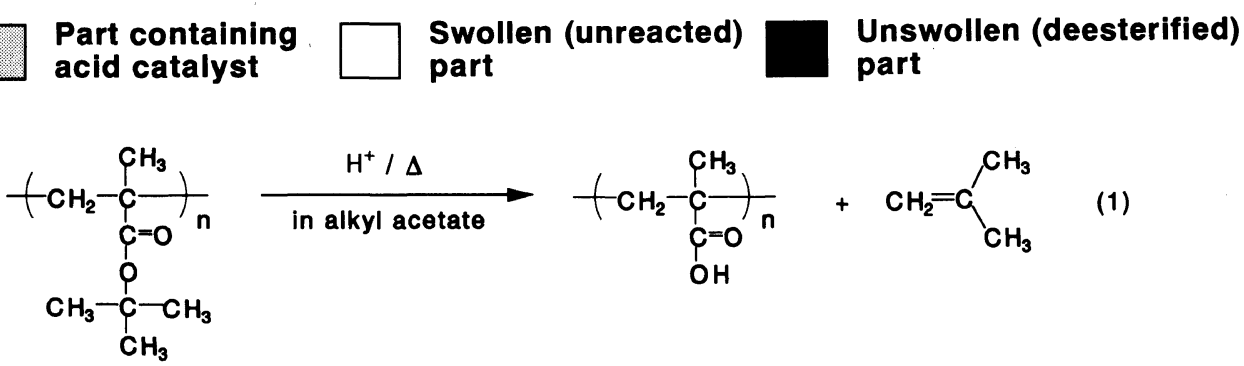<smiles>C=C(C)C</smiles>

Scheme 1. Procedure for synthesis of gel capsule.

\footnotetext{
† To whom all correspondence should be addressed.
} 
with $1.0 \mathrm{wt} \%$ of $p$-toluenesulfonic acid. The reaction was carried out at $110^{\circ} \mathrm{C}$ for more than $5 \mathrm{~h}$ to give gel capsule, and was recorded by a digital video camera (Sonny, DCR-VX1000). $r_{t}$, the radius of unswollen part after $t=t$ min, was periodically measured by a micro-computer image processing. ${ }^{4}$ The homogeneously deesterified gel (degree of deesterification, $79.0 \mathrm{~mol} \%$ ) was prepared from the reaction of a gel sample with $1.0 \mathrm{wt} \%$ of $p$ toluenesulfonic acid in a chamber at $110^{\circ} \mathrm{C}$ for $3 \mathrm{~h}$.

Chemical release was carried out as follows. The gel capsule $\left(r_{\infty} / r_{0}=0.74\right)$ was dipped into a solution $(0.1$ $\left.\mathrm{mmol} / \mathrm{L}^{-1}\right)$ of Rose-Bengal in methanol-acetone mixture $(1: 1)$ and allowed to swell for 1 day at $30^{\circ} \mathrm{C}$. After drying, the shell layer was selectively washed with acetone by a Soxhlet extractor and dried. The sample was placed in $300 \mathrm{~mL}$ water at $50^{\circ} \mathrm{C}$. The change of absorbance of the solution at $548 \mathrm{~nm}$ was measured on a UV photometer.

\section{RESULTS AND DISCUSSION}

A cylindrical GPBM (length the same as diameter, $3 \mathrm{~mm}$ ) was synthesized from the copolymerization of $t$-butyl methacrylate with $5 \mathrm{~mol} \%$ of divinylbenzene in Teflon tubes in toluene. GPBM containing acid catalyst is prepared as follows: GPBM was swollen in chloroform solution of $p$-toluenesulfonic acid and dried at room temperature. Deesterification could hardly be detected when this operation was carried out at room temperature. When the gel with acid catalyst was heated above $90^{\circ} \mathrm{C}$, deesterification occurred to give a transparent gel, while the deesterification of poly( $t$-butyl acrylate) gel afforded a foam gel under the same conditions. When the gel was placed in heated alkyl acetate for a long time, it started to swell from the outer surface. The radius of unswollen part decreased and came close to constant value (Scheme 1). At the end of the reaction, the gel was divided into a swollen shell and an unswollen core. The shell of the obtained gel was not swollen in water and methanol, although the core was swollen well in these solvents. The IR spectra of the shell and core parts are shown in Figure 1. The spectrum of shell part agreed with that of PBM. The spectrum of core part showed strong absorption at $1704\left(\mathrm{C}=\mathrm{O}\right.$, stretching) and $3400 \mathrm{~cm}^{-1}(\mathrm{O}-\mathrm{H}$, stretching). This was consistent with PMAA. The spectra indicated the degree of deesterification very high in the unswollen parts and deesterification to hardly occur in the swollen part. In the reaction, the solvent diffused in the gel prevented deesterification and the solvent did not diffuse in the deesterified gel part. Therefore, a core-shell typed gel consisting of a hydrophilic deesterified core and hydrophobic unreacted shell was produced at the end of the reaction.

When a cylindrical GPBM was used, the cylindrical shape of unswollen part was similar to the original until high conversion. The reaction was recorded by a digital video camera. $r_{t}$, which is radius of unswollen part after $t=t \mathrm{~min}$, was measured by a micro-computer image processing. ${ }^{4}$ When the gel was considered as an infinite cylinder, the volume ratio $(x)$ of the unswollen core to the original gel was determined as a function of $r_{t} / r_{0}$ (eq 2). The apparent reaction can be followed as a function of $r_{t} / r_{0}$. The reaction was carried out in various alkyl

Polym. J., Vol. 29, No. 9, 1997

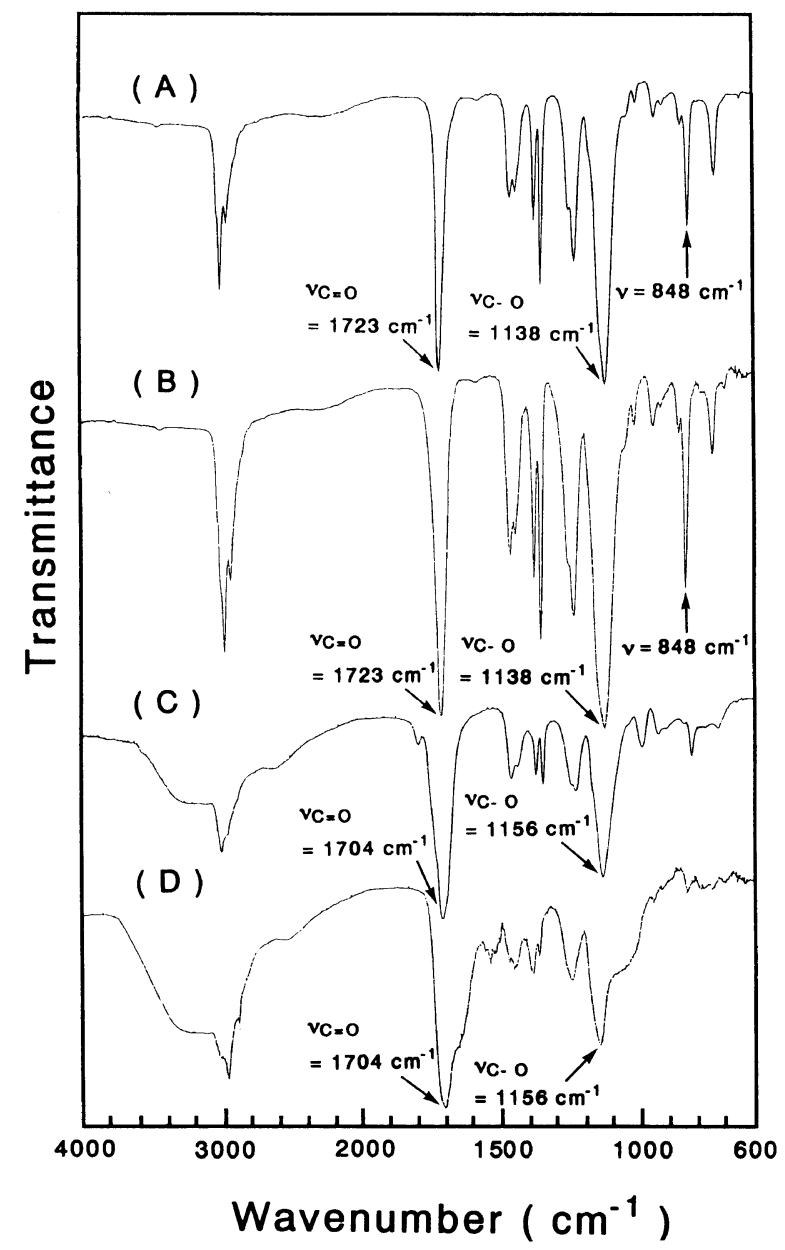

Figure 1. IR spectra of (A) soluble poly(t-butyl methacrylate), (B) shell part of the gel, (C) soluble poly(methacrylic acid), and (D) deesterified core part of the gel.

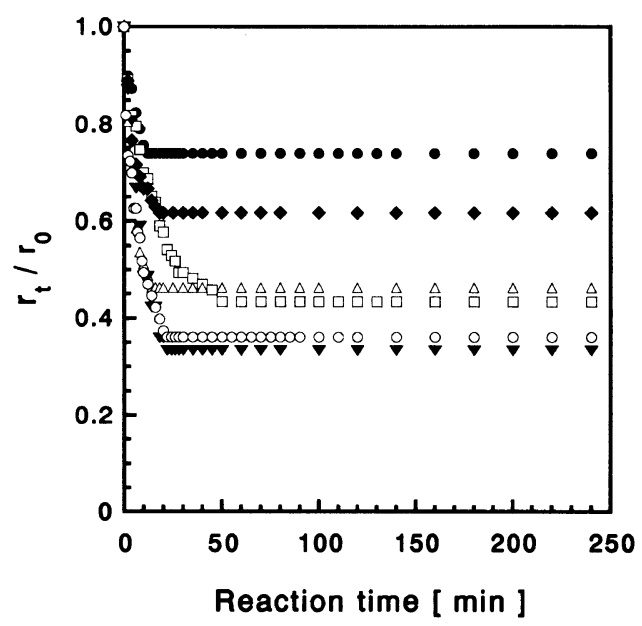

Figure 2. Change in the radius $\left(r_{t} / r_{0}\right)$ of unswollen part of the gel in various alkyl acetates: $(\bigcirc) n$-dodecyl acetate; $(\square)$ 2-ethylhexyl acetate; $(\diamond) n$-octyl acetate, $(\triangle) n$-hexyl acetate; $(\nabla) 2$-methylbutyl acetate; (O) $n$-pentyl acetate at $110^{\circ} \mathrm{C}$.

acetates at $110^{\circ} \mathrm{C}$ (Figure 2). $r_{\infty} / r_{0}$ decreased with increasing alkyl length of solvent. $r_{\infty} / r_{0}$ depended on reaction temperature and acid concentration. These results suggest that the final core size is controlled by the diffusion of the solvent and deesterification rate. 


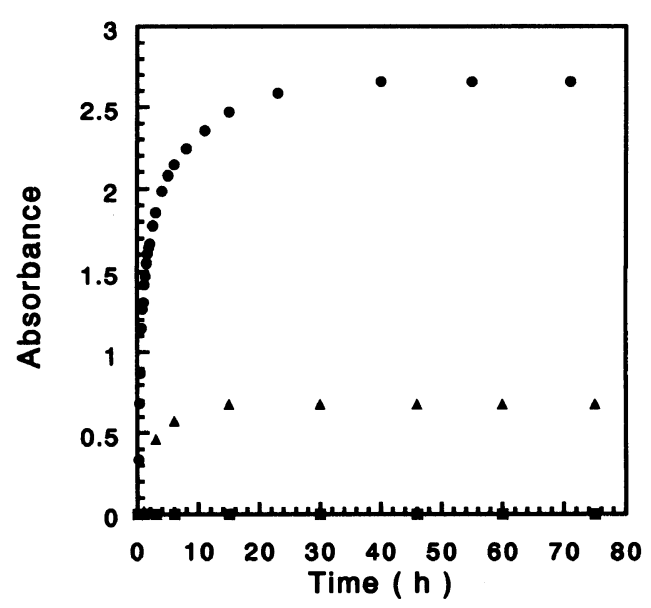

Figure 3. Change in absorbance of the aqueous solution with the gel: (O) homogeneously deesterified gel (degree of deesterification, $79.0 \mathrm{~mol} \%)$ with Rose-Bengal $;$; ( $\Delta)$ gel capsule $\left(r_{\infty} / r_{0}=0.74\right)$ containing Rose-Bengal in the core part; $(\boldsymbol{\square})$ gel capsule $\left(r_{\infty} / r_{0}=0.74\right)$ containing Rose-Bengal in the core part aged at $120^{\circ} \mathrm{C}$ for $1 \mathrm{~h}$, at $548 \mathrm{~nm}$.

${ }^{\text {a }} 500 \mathrm{ml}$ water was used.

$$
x=1-\left(\frac{r_{t}}{r_{0}}\right)^{2}
$$

It is easy to introduce chemicals into the core part of a gel when the gel is dipped into a methanol-acetone mixture and washed with acetone. Release of RoseBengal from the gel capsule was carried out in water at $50^{\circ} \mathrm{C}$ (Figure 3). When the gel capsule and homogeneously deesterified gel were used, release of Rose-Bengal from the gels was complete in $30 \mathrm{~h}$. The shell layer did not affect permeability. However, the release of RoseBengal was not detected in 1 week when the gel capsule aged at $120^{\circ} \mathrm{C}$ for $1 \mathrm{~h}$ was used. The aged shell layer may possibly serve as a permeability barrier for many chemicals including Rose-Bengal. The chemical release from the gel capsule seems controlled by the thickness of the shell layer and aging.

Further studies on the deesterification of GPBM gels and release from the obtained gel capsule are now in progress.

Acknowledgment. This work was partly supported by a Grant-in-Aid for Scientific Research (No. 08651053) from the Ministry of Education, Science, and Culture of Japan, for which we are grateful.

\section{REFERENCES AND NOTES}

1. a) C. G. Willson, H. Ito, J. M. J. Fréchet, T. G. Tessier, and F. M. Houlihan, J. Electrochem. Soc., 133, 181 (1986).

b) M. Ueda and H. Ito, J. Syn. Org. Chem. Jpn., 49, 437 (1991).

2. H. Ito and M. Ueda, Macromolecules, 21, 1475 (1988).

3. T. Iizawa and F. Matsuda, Polym. Prep., Jpn., 45, 1796 (1996).

4. The analysis was performed on a Macintosh computer using the public domain NIH Image program. 